\title{
Territoriality is just an option: allocation of a resource fundamental to the resource defense polygyny in the European wool carder bee, Anthidium manicatum (Hymenoptera: Megachilidae)
}

\author{
Karsten Seidelmann ${ }^{1}$ (D)
}

Received: 17 May 2021 / Revised: 23 August 2021 / Accepted: 26 August 2021 / Published online: 13 September 2021

(c) The Author(s) 2022

\begin{abstract}
The wool carder bee Anthidium manicatum is one textbook example of resource defense polygyny among solitary bees, known for intense male-male competition, forced copulations, and the extreme form of interspecific territoriality toward other flower visitors. This mating system depends on the spatial structure of the defended resource and requires several adaptations in males. The allocation of patches with host plants as well as male body size and phenology was analyzed over 3 years in the diverse habitat of a botanical garden. Anthidium manicatum males searched in groups up to 12 individuals a wide diversity of patches with various food plants of foraging females. Territories were established in small high-quality patches only. Males abandoned aggressive and territorial behavior in large patches. Available patches were occupied by males of the various body size fractions independently of each other according to patch profitability. The higher competitive weight of large males in small patches compared to spacious ones was balanced by an opposing correlation of patch profitability. Although the mating system in A. manicatum is clearly a resource defense polygyny, males were found to be plastic in their behavior, and territoriality was not consistently observed. Mate acquiring tactics, be they territory holder (bourgeois), sneaker, floater, or scrambler for mating, can be considered to be different behavioral phenotypes within one environmentally sensitive conditional strategy.
\end{abstract}

\section{Significance statement}

Territoriality is a rare and derived pattern in solitary bee mating behavior. In most cases of territoriality, males defend rendezvous places to meet freshly emerged, virgin females. While this type of mating behavior fits still into the framework of ancestral monandry of aculeate Hymenoptera, the continually polyandric resource defense polygyny found in the genus Anthidium is highly derived. Males occupy flower resources exploited for larval provisions and extort copulations from provisioning nesting females. Territoriality in Anthidium does not lead to a monopolization of females, the exclusion of many competitors from reproduction, and a reduction of sperm competition as is typical for resource-based mating systems. Contrary, Anthidium is a highly promiscuous species and both males and females are lifelong engaged in copulations with multiple mates. Also, the allocation of the resource fundamental to the defense polygyny was found to be more fairly balanced than expected. This study diversifies the mating system of anthidiine bees and demonstrates unusually high plasticity in the resource allocation of a territorial species.

Keywords Mating system · Polygynandry $\cdot$ Unequal competitors $\cdot$ Truncated phenotypic distribution $\cdot$ Ideal free distribution $\cdot$ Behavioral phenotype $\cdot$ Conditional strategy

Communicated by O. Rueppell.

Karsten Seidelmann

karsten.seidelmann@zoologie.uni-halle.de

1 Institute of Biology/Zoology, Department of Animal Physiology, Martin-Luther-University, Hoher Weg 8, 06120 Halle (Saale), Germany

\section{Introduction}

Territorial behavior is an extreme form of sharing resources by individuals in which some individuals ensure their exclusive usage of a part of resources by agonistic behavior. The feasibility to exclude conspecifics depends on the 
opportunity to economically defend a resource (Brown 1964; Kokko et al. 2014). The benefits arising from the exclusive usage of a resource have to be higher than the costs to keep competitors out (Kemp 2018). In bees, one or more prerequisites for an economical resource defense are usually not met. Therefore, territoriality is a rare derived, rather than an ancestral, phenomenon in Apoidea (Alcock 1980, 2013b; Barrows 1975; Paxton 2005). However, there are a few species in that males are able to establish territories to get exclusive or at least preferential access to mating. One strategy to monopolize receptive females is the defense of nesting sites from which virgin females emerge (e.g., Centris pallida, Amegilla dawsoni (Alcock 1996; Alcock 1997; Alcock 2013a; Alcock et al. 1977b)). This strategy appears to be straightforward as monandry in females is the ancestral state in Aculeata (Hughes et al. 2008). Another strategy is the monopolization of food plants in cases where females are specialized on a few host plant species (oligolectic) and host plants are aggregately distributed over the landscape (e.g., Hoplitis anthocopoides (Eickwort 1977), Pachymelus limbatus (Nilsson and Rabakonandrianina 1988)). If males start to defend food plants not only as rendezvous places for freshly emerged, virgin females but as sources of larval provisions, they could extend their mating opportunities over the whole reproductive period of females. However, this evolution in the mating strategy of males has inevitably to be accompanied by a coevolution from monandry, as occurs in most solitary bees (Alcock 1980, 2013b; Hughes et al. 2008; Paxton 2005), to lifelong receptivity in females. Only a few species of wool carder bees (Anthidium) are known to have made this transition to a continually polyandric resource defense polygyny (Alcock 2013b; Alcock et al. 1977a; Garcia and Ornosa 1999; Jaycox 1967; Paxton 2005; Sugiura 1991; Villalobos and Shelly 1991).

The European wool carder bee, Anthidium manicatum, is meanwhile a nearly worldwide distributed species (Gibbs and Sheffield 2009; Graham and MacLean 2018; Soper and Beggs 2013; Strange et al. 2011). Males defend food plants (Barrows 1975; Pechuman 1967; Severinghaus et al. 1981) and belong to the most aggressive males of all bee species showing even interspecific territoriality. Anthidium manicatum males chase and sometimes even harm almost any insect except conspecific females encountered at flowers in their territories (Barrows 1975; Graham et al. 2019; Pechuman 1967; Severinghaus et al. 1981; Wirtz et al. 1988). This territorial behavior of large males is flanked by typical alternative mating tactics. Small males attempt to gain fertilizations by sneaking up to females without being detected by territory owners (Schick and Sukopp 1998; Starks and Reeve 1999).

The evolution of a despotic mating system in Anthidium was based on a specialization of females to a few host plants (Alcock 2013b; Lampert et al. 2014) and should result in several features: First, males have a prolonged voltinism that covers the total activity period of conspecific females, not only the time span of female emergence (Thornhill and Alcock 1983). Second, male body mass increased to improve competitiveness leading to a distinct male-biased sexual size dimorphism (SSD) that is typical for resource defense polygyny (RDP) with prominent male-male competition, territoriality, and forced copulations (Alcock 2013b; Blanckenhorn 2005). Third, large males with the highest resource holding potential occupy all available territories, expelling smaller competitors into the unprofitable matrix and exclude them from any access to mating. This should lead to an extremely truncated phenotype distribution. Due to this ousting, fourth, abandoned territories are taken over by considerably smaller males lurking in the matrix. Fifth, females should adjust their maternal investment to the described conditional mating tactics (Schick and Sukopp 1998; Starks and Reeve 1999) by investing either in large (territory holders, bourgeois) or small (satellites) sons leading to a distinct size dimorphism in males (Alcock 2013b).

The territorial manifestation of the RDP in A. manicatum has hitherto been exclusively described (Müller 1987; Pechuman 1967; Severinghaus et al. 1981; Starks and Reeve 1999; Wirtz et al. 1988). However, also the RDP in Anthidium depends on the allocation of resources females depend on between males. The ability to monopolize resources is inherently sensitive toward the spatial structure and the number of males that compete for territories (Alcock et al. 1978; Emlen and Oring 1977; Kemp 2018; Kokko et al. 2014). The robustness of resource allocation and resulting adaptations in a RDP have rarely been addressed though. The Botanical Garden of the University of Halle (Saale), Germany, provides ideal conditions to study the outcome of a stress test on territoriality. The garden tenders a great variety of patches containing food plants of A. manicatum both in terms of species composition and size. The area furthermore hosts a dense wool carder bee population confronting territory owners with a large number of competitors. Large patches with dense vegetation and many competitors are difficult conditions for the economic feasibility to monopolize access to mates by A. manicatum males. In this study, the harsh conditions found in the Botanical Garden Halle were used to study the resilience of territoriality with the core property of a truncated phenotype distribution and the implementation of the aforementioned four predictions pertaining to phenology and body size.

\section{Methods}

\section{Study area and spatial structure}

The study was conducted in the Botanical Garden of the University of Halle-Wittenberg (Germany, Saxony-Anhalt: 
$51^{\circ} 29^{\prime} 04^{\prime \prime} \mathrm{N} ; 11^{\circ} 56^{\prime} 07^{\prime \prime} \mathrm{E}$ ) from 1997-1999. The garden is situated in the city center of Halle (Saale) surrounded by urban development, a cemetery, and the holm of the river Saale occupied by parks with tree-lined lawns. The area has an altitude above sea level of $94 \mathrm{~m}$ and occupies an area of $4.5 \mathrm{ha}$. The inventory of the garden counts ca. 12,000 species from throughout the world. The climate is moderately warm (Köppen and Geiger classification: $\mathrm{Cfb}$ ) with mean temperatures of $+0.3{ }^{\circ} \mathrm{C}$ and $+18.7^{\circ} \mathrm{C}$ in January and July, respectively, and an annual precipitation of $502 \mathrm{~mm}$. All patches with host plants (mainly Lamiaceae such as Stachys and Teucrium species, Ballota nigra) were mapped (Online Resource 1) and the whole area was occupied by flowering herbaceous perennials within the garden was regularly screened for the presence of A. manicatum males. Spatial relations of the patches with host plants within the study area were determined on the basis of a detailed map of the Botanical Garden containing all beds as well as the road network and all buildings. A map grid was projected over this map with the origin just outside the south-western corner of the garden (Online Resource 1). The distances between all patches were calculated as beelines between the centers of the patches. As patch distances were discontinuously distributed, they were divided into 10 equivalent classes based on the deciles for statistical analysis.

\section{Male identity and body size}

Males of A. manicatum were active from early June till late August. All spots with flowering food plants were inspected at regular intervals on days with favorable weather conditions (mean interval between inspections: $1997=2.6 \pm 1.6$ days, $1998=2.3 \pm 1.8$ days, $1999=3.1 \pm 2.5$ days, overall: $2.7 \pm 2.0$ days). All spots with host plants were visited and all males patrolling the patch were netted and identified. At their first capture, males were weighed with a laboratory fine balance to the nearest $0.1 \mathrm{mg}$ (housed in the garden during the flight period) and individually marked with numbered colored honey bee tags (commercial Opalite tags for marking Apis-queens). The weight of the tag $(1.23 \pm 0.06 \mathrm{mg}$, glue $\approx 0.5 \mathrm{mg}$ ) was corrected for repeated weighing. To generate a mass reference for females, on randomly chosen days in June and July, all females visiting a rich patch within $10 \mathrm{~min}$ were captured and weighed. In addition to male body mass, head width and intertegular span (Cane 1987) were measured by a linen tester to the nearest $0.1 \mathrm{~mm}$ for all individuals caught in 1997 to establish comparability to other studies (Online Resource 2). Body mass was measurable with much higher precision $(\mathrm{g} \leq 0.16 \%)$ on a vital bee in the field than lengths $(\mathrm{g} \geq 2.08 \%$, see Online Resource 2). In contrast to the solid exoskeleton, however, body mass might vary due to food intake and senescence. To access the variability of individual body mass between measurements, males marked in 1997 were weighed at each recapture. Age-related body mass change was established by linear regression analysis of percentage deviations from the individual mean.

\section{Male abundance and site fidelity}

The number of males simultaneously present in the study area changed between observation days and years. The relative abundance $\left(b_{r}\right.$ as actual number referred to the max. number of simultaneously present males per year) was fitted for each year by a 3 parameter Lorentzian peak model ( $d$ as day in flight season):

$b_{r}(d)=\frac{b_{r 0}}{1+\left(\frac{d-d_{0}}{w}\right)^{2}}$

The estimated parameter $d_{0}$ indicates the day with the highest estimated abundance, $b_{r 0}$ is the estimated $b_{r}$ at peak, and $w$ gives the half peak breadth at half peak height. Based on $d_{0}$, the season dates of 1998 and 1999 were adjusted to the reference point in 1997 to correct for different weather conditions. An overall curve of relative abundance was fitted to check the voltinism by systematic deviations of data from a peak curve.

Males were expected to be caught several times. However, males have different probabilities of being captured depending on their success to establish a territory. The frequency distribution of captures $(f(k)$ as the probability of $k$ captures) was approximated by a log-series distribution (Fisher et al. 1943):

$f(k)=\frac{-1}{\ln (1-a)} \cdot \frac{a^{k}}{k}$

A large value of $a$ implies low site fidelity with many males floating around the habitat. The parameter is thus a measure of "non-territoriality" within the male population. The accuracy of adjustment was tested by a $\chi^{2}$-test. The impact of body mass on capture probability was analyzed by ANOVA with year as a random factor. To achieve a nearly homogenous data matrix, numbers of captures were grouped into 6 classes $(1,2,3,4-5,6-7, \geq 8$ captures).

\section{Structure and dynamic of male groups}

In all years, there were more $A$. manicatum males active than patches with host plants available in the Botanical Garden. Males joined into groups of up to 12 rivals. To achieve a nearly homogenous observation matrix, groups had to be assigned into 6 competitor classes $(1,2,3,4-5,6-8, \geq 9$ males). The impact of group size on the average body mass of males found in these groups was determined by a 
univariate ANOVA. Males that were caught in two successive inspections were analyzed for the impact of their body mass and the number of competitors on their decision to continue at a patch ("resident") or to switch to another one ("shift") by a binominal-logit GLM. The impact of male body mass on the shift distance and possible differences between years were explored by an ordinal probit GLM. The outcome of a shift was calculated as the difference of competitors (see the classification of male groups above) in the abandoned and moved in patches. Changes in the ownership of "typical" territories (one territory holder alone or accompanied by a satellite) were analyzed by calculating the body mass difference of successive minus previous owner and testing the mean against zero by a one-sample $t$-test. Males that were observed in two different patches on the same day were considered floaters. This behavioral tactic was analyzed in regard to consistency, male body mass (normal identity GLM), and distances of patches that were floated $\left(\chi^{2}\right.$-test).

SPSS package was used throughout (Ver. 24.0; IBM, Armonk, NY, USA). Normal distribution of data was tested by a Kolmogorov-Smirnov test with Lilliefors corrected $P$-values. Values in the text and figures are given as mean \pm standard deviation or median [Q1; Q3] unless otherwise stated. The error level was set to $\alpha=0.05$.

\section{Results}

\section{Body size and sexual size dimorphism}

Anthidium manicatum males were clearly larger than conspecific females (Fig. 1). Body sizes of both males and females were normally distributed (males: $n=356$, $Z=0.044, P=0.174$; females: $n=97, Z=0.042, P>0.200$ ). Mean body mass of all captured males was $133.1 \pm 31.75 \mathrm{mg}$ while females were significantly lighter $(84.7 \pm 9.65 \mathrm{mg}$; $T=14.816, d f=451, P<0.001)$. Males show also remarkable size differences with body masses ranging from 60.8 to $216.2 \mathrm{mg}$ (coefficient of variation $(\mathrm{CV})=0.238$ ) while variability of body mass in females was much smaller $(C V=0.114)$. Body mass of males did not differ between study years (1997: $n=162,1998: n=95,1999: n=99$, ANOVA, $F_{2,355}=2.916, P=0.055$; Online Resource 3, Fig. S1).

Variability of body mass of repeatedly captured males was low (46 males weighed $\geq 3$ times, $n=185$, mean relative difference between succeeding weightings $=-0.116 \pm 2.685 \%)$. Individual body mass decreased slightly with age (Online Resource 3, Fig. S2; $K=-0.245$, $P<0.001)$. However, age-related body mass loss was so tiny (linear regression of body mass change by age, $b=-0.062 \%$ per day, $P=0.001, R^{2}=0.060$ ) that it did not become manifested as a significant decrease of body mass of newly

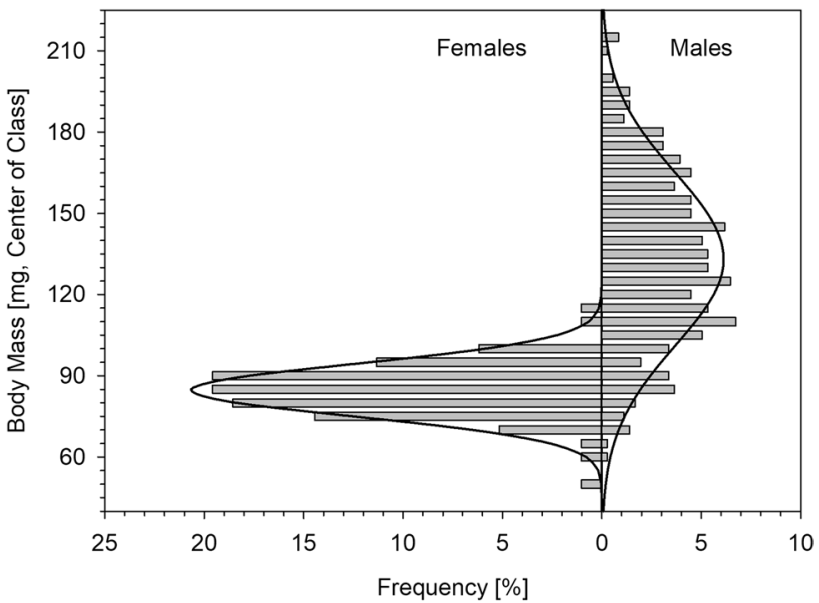

Fig. 1 Body mass of A. manicatum individuals captured in the Botanical Garden Halle over 3 years. Class width $5 \mathrm{mg}$, left panel: females, right panel: males, solid lines: fitted normal distributions

captured males over the season (partial correlation with year as control variable: $K=-0.051, d f=352, P=0.335$ ).

\section{Male abundance and patch structure}

The abundance of $A$. manicatum males was unimodal with the highest male numbers at season day $40.47\left(R^{2}=0.826\right.$, $F_{2,65}=149.377, P<0.001$; Fig. 2$)$. Up to 53 males were simultaneously observed within the study area (total mean $20.45 \pm 12.98$ males, $n=66$, Online Resource 3, Table S1). Males were found searching for females in 29 patches containing 46 species of flowering plants out of 23 genera and 6 families (Online Resource 3, Table S2). Patches were distributed throughout the Botanical Garden. The distance between patches ranged from 2.6 to $172.4 \mathrm{~m}$ (median $86.9 \mathrm{~m}, n=406$; median distance to nearest patch $10.2 \mathrm{~m}$ ). The patch area covered by host plants (mean $1.37 \pm 1.48 \mathrm{~m}^{2}$ ) ranged from $0.2 \mathrm{~m}^{2}$ (a single Stachys plant) to $7.5 \mathrm{~m}^{2}$ (a dense, closed stand of Teucrium scorodonia). One "patch" sized about 50 $\mathrm{m}^{2}$ : an area with sparse vegetation and interspersed small individuals of Marrubium, Teuricum, and other Lamiaceae (total of 12 species, this region was not included in the calculation of mean patch area). Due to landscaping and care work in the garden, only 10 patches were available to the bees throughout all three observation years.

\section{Recapture of individual males}

The number of captures of individual males was log-scale (logarithmic) distributed both for all years as on a yearly basis (Fig. 3; Online Resource 3, Table S3). The capture frequency distribution remained the same in all years $\left(\chi^{2}\right.$ test: $\left.n=365, d f=20, \chi^{2}=28.364, P=0.101\right)$. Males showed a low site fidelity as the overall non-territoriality parameter 


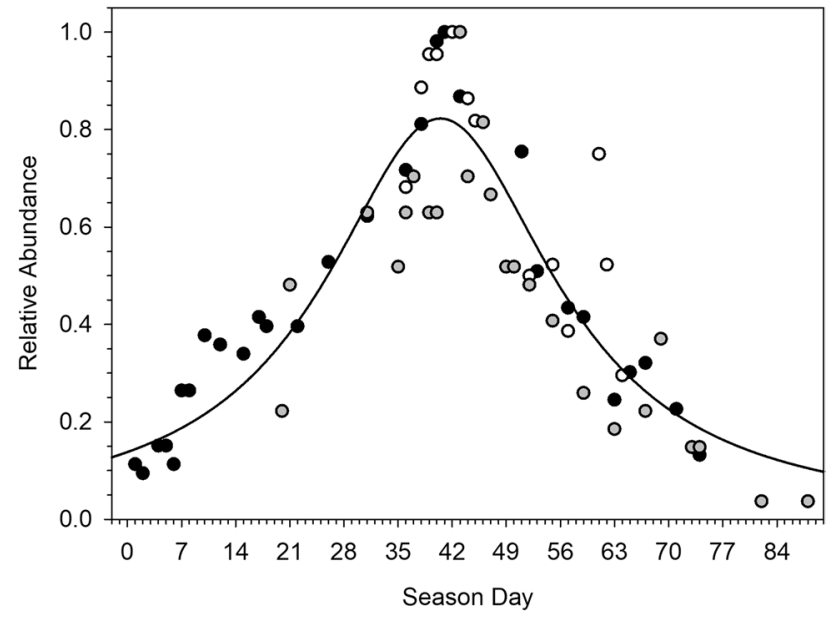

Fig. 2 Relative abundance of A. manicatum males in the Botanical Garden Halle. Dots indicate the number of individuals observed per day, referred to the maximum number of individuals observed on a single day of the particular year (rel. abundance). Black circle: 1997, gray circle: 1998, open circle: 1999, solid line: Lorentzian peak function fitted to the pooled data of all 3 years. Please note that the markers of the maximum male number observed per year were slightly shifted to the left and right, respectively, to increase the readability of the figure

$a$ accounted to 0.782 . Body mass did not differ between capture classes in general (captures $F_{356,5}=3.039, P=0.057$; year $F_{356,2}=2.800, P=0.092$, interaction $F_{356,10}=1.235$, $P=0.267)$. Only the marginal classes $(1, \geq 8)$ were different (Fig. 4). Most often caught males had a higher mean body mass than single day visitors (Scheffé post hoc: difference $23.6 \mathrm{mg}, P=0.027$; all other $P \geq 0.090$ ).

Males were observed for a maximum of 43 days based on a total of 1043 observations. Nearly half of the males

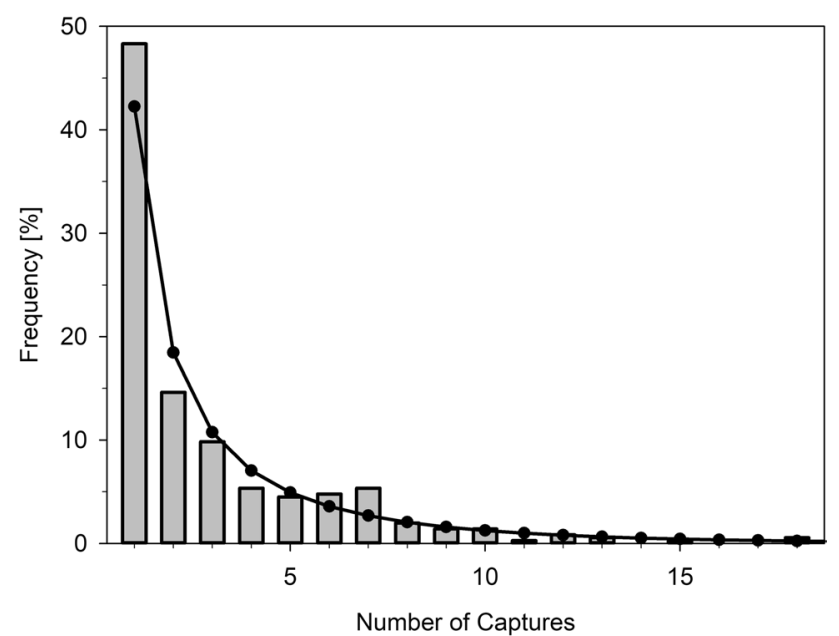

Fig. 3 Capture frequency of individual males observed in the Botanical Garden Halle in the years 1997-1999. Dots and solid lines refer to a fitted log-series distribution
(48.6\%) were captured only once $(n=173)$. The minimum lifetime (or observation period) of repeatedly observed males (mean $14.3 \pm 10.6$ days, median $=11$ days, $n=182$ ) was skewed to the right $\left(\gamma_{\mathrm{m}}=0.786\right.$, se $=0.180$, Online Resources 3, Fig. S3). The minimum lifetime of males did not correlate with body mass (partial correlation with season date as control variable, start of season: 1st June, observations $>1$ : $R=0.019, d f=179, P=0.801)$.

\section{Composition of male groups}

Up to 12 A. manicatum males were found simultaneously in one patch with flowering food plants. Groups of males were composed of competitors of all sizes (Fig. 5). Body mass of males differed between groups with various numbers of competitors (Fig. 6; $n=1176, F_{1176,5}=18,287$, $P<0.001)$. However, the differences were less than $26.5 \mathrm{mg}$ ( $\leq 17 \%$ of the general variation in body mass) and the variance explained by group size was rather small $\left(R^{2}=0.072\right)$. Only the body mass of males in patches without competitors was systematically higher than the body mass of males accompanied by competitors (Scheffé post hoc: all differences of means in the range between 15.0 and $26.5 \mathrm{mg}$, all $P<0.001)$. Differences between all other groups ranged between $11.5 \mathrm{mg}(P<0.001)$ and $0.9 \mathrm{mg}$ $(P=0.823)$. Territorial behavior was observed only by big males in small patches of preferred food plants accompanied by no more than one satellite. Males abandoned aggressive behavior in larger groups and male-male interactions became rare.

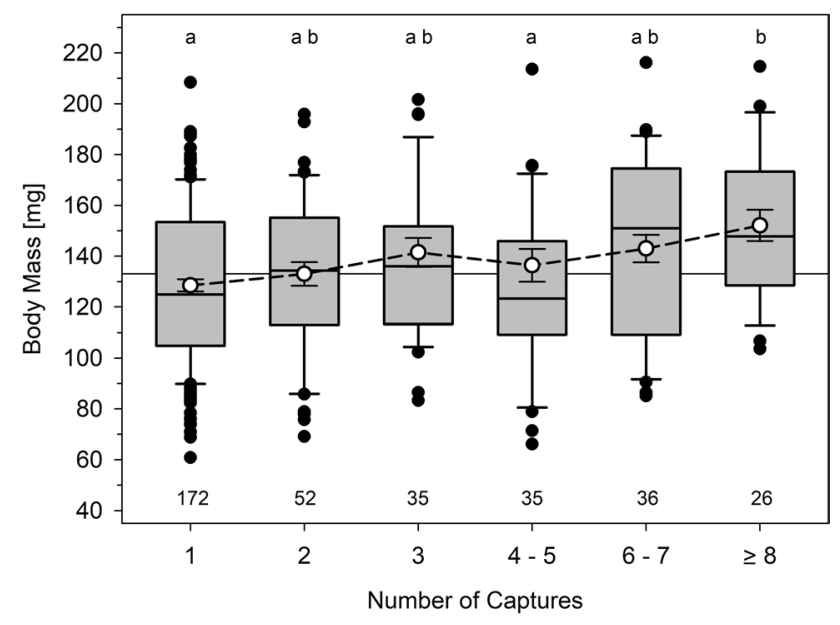

Fig. 4 Body mass of males with different capture frequencies. Box plots indicate 10th, 25th, 50th, 75th, and 90th percentiles, dots indicate outliers, open circles with error bars and dashed line refer to estimated means and se, solid line represents the overall mean body mass of all males caught, numbers of males per class are given over the $\mathrm{x}$-axis, letters indicate homogenous subgroups 


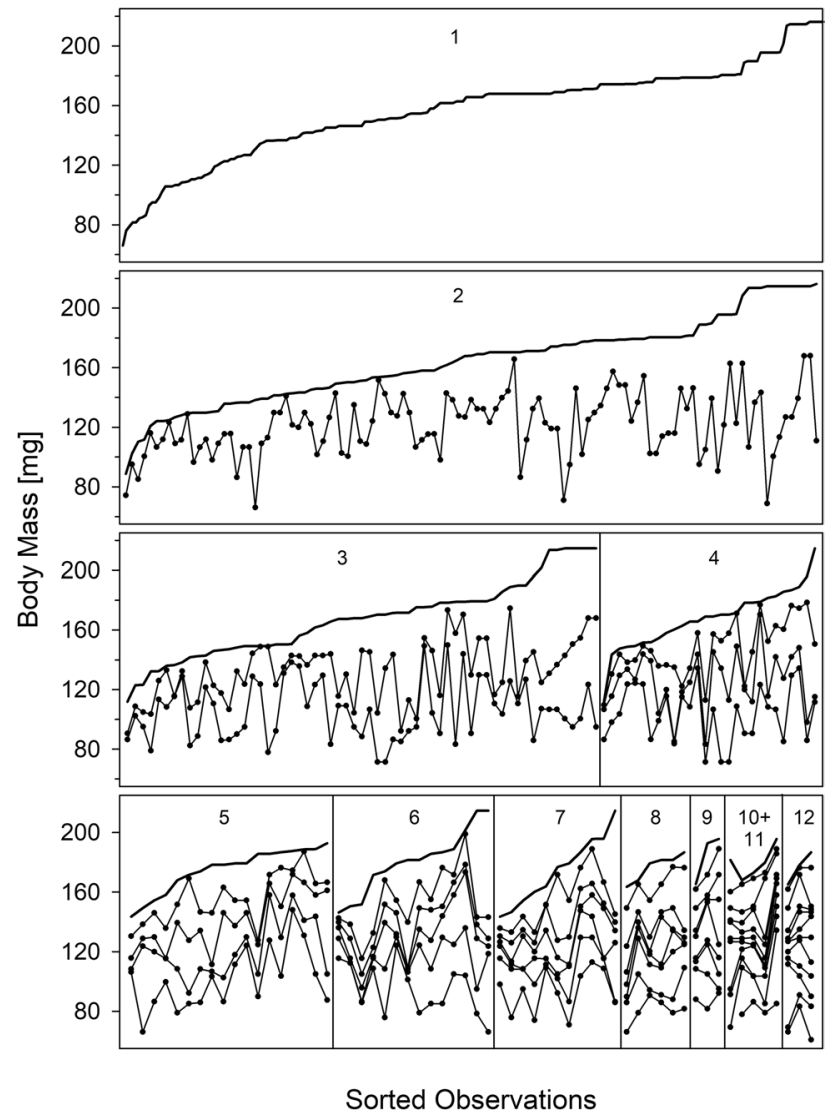

Fig. 5 Composition of A. manicatum male groups in regard to body mass of individuals. Observations were sorted by the mass of the largest male and all individuals within a group in ascending order. Individuals are identified as dots; males of the same serial number of adjacent groups are connected by lines to clarify the association. The number of males in a group is given on top of the respective panel

\section{Dynamics of patch use by males}

Males could stay within a patch for several days or leave the patch to search for females elsewhere. When males changed the patches they moved on average $43.5 \mathrm{~m}$ [9.5 m; $89.6 \mathrm{~m}](n=371)$. Males did not randomly shift (relocate) between available patches (Fig. 7a-c): Between many of the patches not one single relocation was documented (292 connections), between some patches one male moved (50 connections), while other patches were connected by many males (64 connections with 297 relocations). In cases of frequent changes ( $>1$ male), there were in 12 cases unidirectional movements from one patch to another but in 52 cases changes occurred in both directions. There were no differences in the mean change distance between years and no influence of male body mass (year: $W_{2,371}=3.974$, $P=0.137$; body mass: $W_{1,371}=1.296, P=0.255$; interaction: $\left.W_{2,371}=3.454, P=0.178\right)$. However, body mass influenced the tendency to stay or to leave while the number of competitors in a patch had no influence on the decision (body

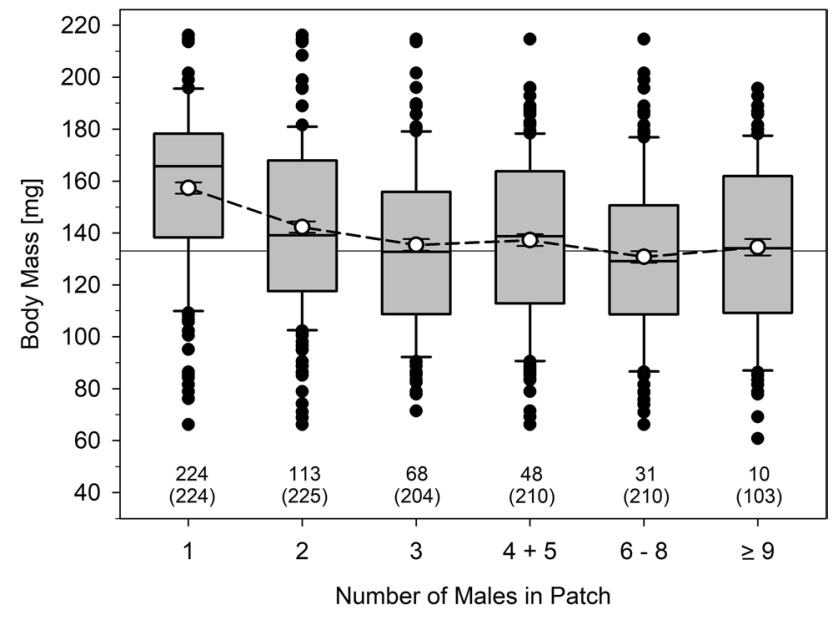

Fig. 6 Body mass of males in dependence on group size. Box plots indicate 10th, 25th, 50th, 75th, and 90th percentiles, dots indicate outliers, open circles with error bars and dashed lines refer to estimated means and se. The solid line indicates the overall mean body mass of all male individuals. Numbers of groups observed are given over the $\mathrm{x}$-axis, numbers in brackets refer to the number of males unless resulting from group size. Individuals appear as often as they were observed, total $n>$ number of individuals. Letters indicate homogenous subgroups

mass: $W_{1,835}=53.070, P<0.001$, group size: $W_{5,835}=7.339$, $P=0.197$, interaction: $W=5.718, P=0.335)$. Males changing the patch tend to be lighter $(135.8 \pm 31.1 \mathrm{mg}, n=503)$ than males staying $(156.0 \pm 31.1 \mathrm{mg}, n=332)$. In general, males were not able to switch to territories with less competitors (Online Resource 3, Fig. S4; group class difference $=0$ $[-1 ; 1], n=351$, Wilcoxon signed-rank: $W=-0.744$, $P=0.457)$.

Also, the ownership of patches occupied by one or two males only changed. The body mass difference of succeeding and previous territory holders was normally distributed $(n=138, Z=0.057, P>0.200)$ and ranged from $-95.4 \mathrm{mg}$ to $79.0 \mathrm{mg}$. The new owner was on average slightly lighter than the previous one $\left(-7.3 \pm 39.1 \mathrm{mg}, T_{0}=-2.166, d f=137\right.$, $P=0.032)$. $34.4 \%$ of all resigned territory holders were found later in other patches (1997: 47.8\%, 1998: 33.3\%, 1999: 14.0\%).

\section{Excursions and simultaneous use of several patches by individual males}

Out of the 356 males observed in the study, 41 males (11.5\%) were absent from a particular patch during one inspection although they were present there before and thereafter. This was assumed to be an excursion to other patches either within the Botanical Garden (20 cases) or unknown patches in the surroundings ( 34 cases). Thirty-three males undertook 1, 5 males 2, 2 males 3, and 1 male even 5 registered excursions during the period they have been observed. On the other hand, 
Fig. 7 Connections between the various patches in the Botanical Garden Halle are expressed by moves of individual males. a-c Ascertained shifts of males in the years 1997 to 1999 , d patches connected by repeated floaters pooled for all years; area of circles represents patch quality estimated by the mean number of males found per inspection, dotted lines: one shift, dashed line 2-3 shifts, solid lines $4-7$ shifts, bold lines $>7$ shifts. Line types refer to numbers of floaters in $\mathbf{d}$, respectively. For a map of the botanical garden and an inventory of host plants, see online resource 1
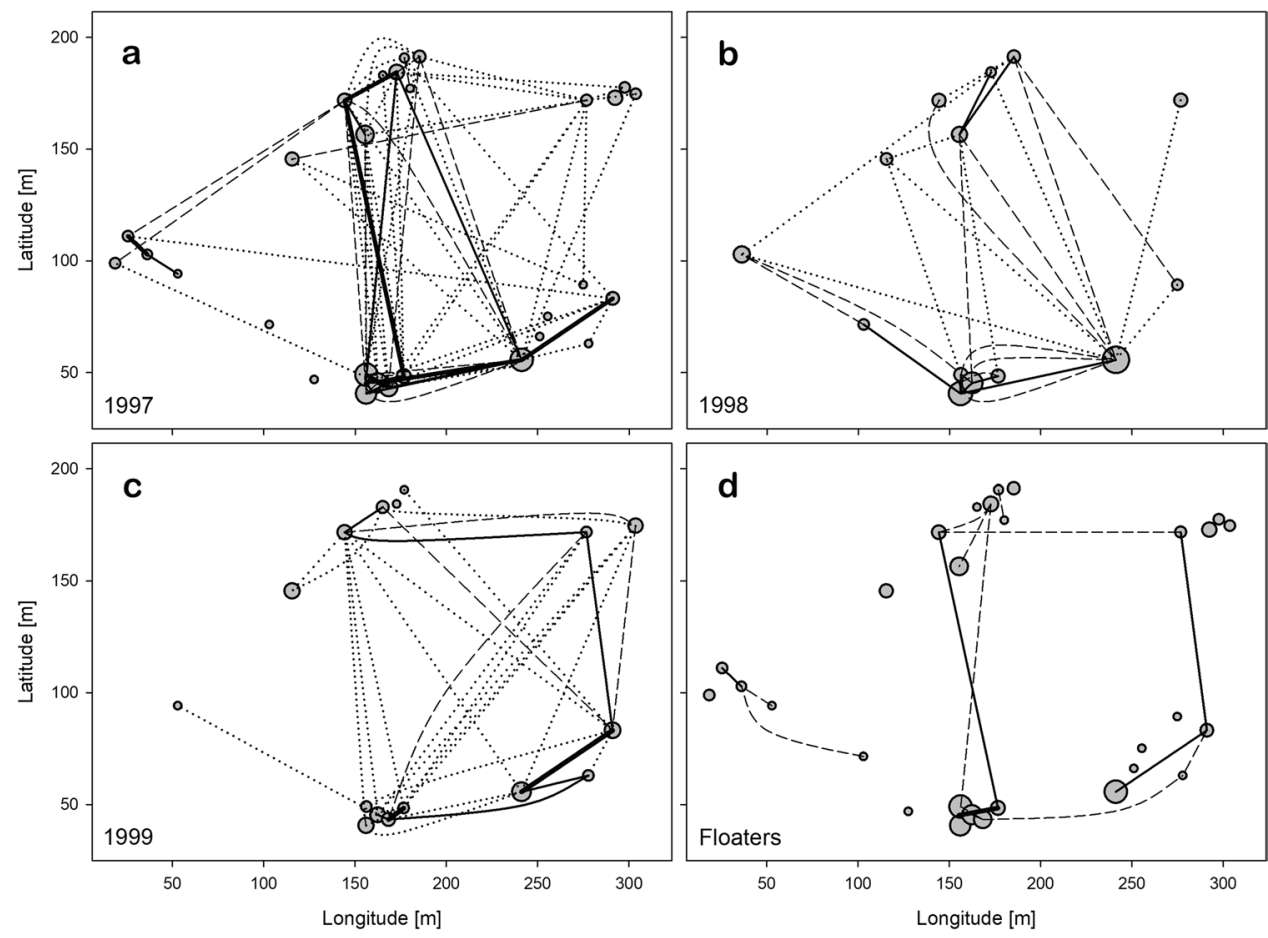

68 males (19.1\%) were captured at two different places within one inspection. Of these males, 13 individuals were seen even on a third patch the same day. The percentage of males detected at different patches within 1 day (assumed to be floaters) was about the same in all 3 years (1997: 21.0\%, 1998: 17.9\%, 1999: 17.2\%). About 54\% of the floaters were observed only on one single day by patrolling in two patches and $46 \%$ were seen on several days in two or three patches ("repeated floaters"). None of the males shuttled between several patches each time when it was observed (max. 67\% of sightings). The longest time span a male was found continuously resident in a territory of two combined patches (distance $9 \mathrm{~m}$ ) was 16 days. The body masses of the three male groups were not different ("resident": $134.1 \pm 31.7 \mathrm{mg}, n=275$; "onetime floater": $128.5 \pm 29.5 \mathrm{mg}, n=37$; "repeated floater": $136.3 \pm 34.9 \mathrm{mg}$, $n=31$; GLM $\left.F_{2,343}=0.619, P=0,539\right)$. Floaters shuttled between patches from 4 to $124 \mathrm{~m}$ apart. The maximum distance over which floaters repeatedly flew back and forth was $88 \mathrm{~m}$ (Fig. 7d, Fig. 8). The frequency distribution of distances between patches toward males shifted was statistically not different from patches that were visited by floaters $\left(\chi^{2}\right.$-test: $n=351, \chi^{2}=13.865, d f=9, P=0.127$; Fig. 8).

\section{Discussion}

Scramble competition polygyny with monandrous females that are receptive immediately after their emergence from the maternal nest is the ancestral state in solitary bees (Hughes et al. 2008; Paxton 2005). The transition to a RDP provoked several adaptations in A. manicatum. One of the fundamental features is the prolonged flight period of males that lasted about 80 days (this study) and covers nearly the whole activity period of females (Schick and Sukopp 1998; Westrich 2018; Wirtz et al. 1992). Although the first prediction of a prolonged flight period in males was met, individual males were observed for shorter time spans of maximal

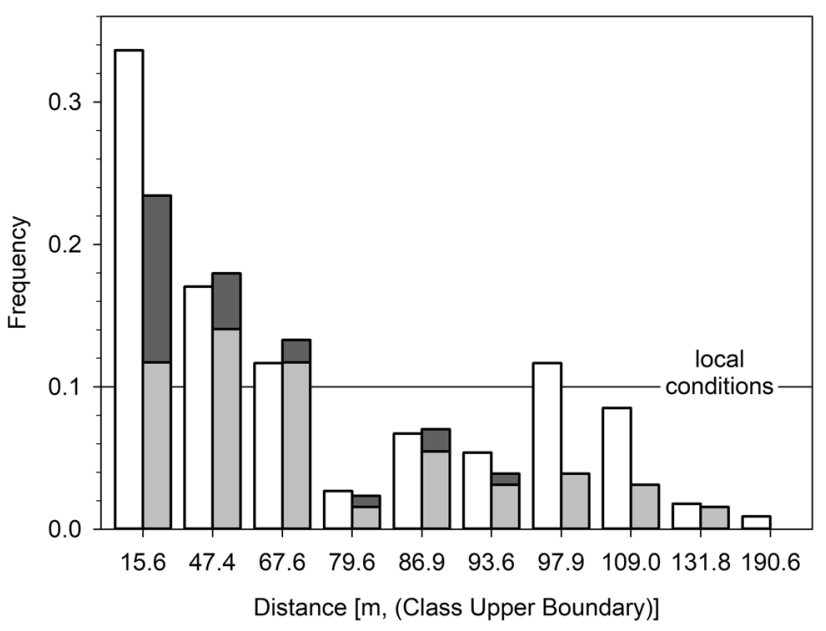

Fig. 8 Distribution of distances between patches of documented shifts and floats in the Botanical Garden Halle. Distances between all patches found in the garden were grouped into 10 equal classes based on the deciles. The equal frequency of all distance classes is indicated by the solid reference line labeled as "local conditions". White columns: shifts to another patch, light gray columns: onetime floats, dark gray columns: patches repeated floaters flew back and forth 
about 40 days with a minimum lifetime of 14.3 days for repeatedly captured males. Forty-nine percent of the males have been seen only once. In another study, these values were measured as 9.5 days and $28 \%$, respectively (Wirtz et al. 1992). The discrepancy between the observed minimum lifetime and the duration of the flight season could indicate a bivoltine life cycle (Müller 1987). However, this hypothesis is contradicted by the general unimodal abundance that was observed in all three observation years in Halle and elsewhere (Schick and Sukopp 1998; Westrich 2018; Wirtz et al. 1992).

The most obvious feature of a RDP is the observed highly male-biased SSD that meets the second prediction. Males were 1.6 times heavier than females (Wirtz et al. 1992: 1.5 times) substantiating high sexual competition. This inverted SSD with a broad size range in males is a distinct pattern compared to most bee species (Stubblefield and Seger 1994), particularly to species with a scramble competition polygyny as Megachile rotundata or Osmia bicornis where males are smaller and of narrower size range than females (O'Neill et al. 2010; Seidelmann 2014). Body size depends in solitary bees on larval provisions stored in a brood cell by the mother. Thus, SSD is the outcome of a maternal provisioning strategy to maximize the fitness reward of invested units of brood care effort (Alcock 2013b; Bosch and Vicens 2005; Kim and Thorp 2001; O'Neill et al. 2010; Seidelmann et al. 2010). Due to the RDP in A. manicatum, a discontinuous distribution of male body size was predicted. Large territorial males can be expected to gain most of the copulations, but they are expensive for their mothers. Small, sneaking males achieve less copulations but are cheap to produce. Consequently, there should be a cost-benefit balance for both types of males as it was observed, e.g., in A. dawsoni (Alcock 1996; Simmons et al. 2000; Tomkins et al. 2001). In contrast to the expected dimorphism (fifth prediction), male body size was normally distributed. Most of the males were of intermediate size. This pattern of a unimodal male body size distribution was found also in other European A. manicatum populations despite an observed territoriality (Müller 1987; Wirtz et al. 1992).

The oligolectic use of host plants is responsible for a clumping of females and forms the spatial prerequisite for a resource defense by males (Alcock 2013b; Alcock et al. 1978; Barrows 1975; Kemp 2018; Nilsson and Rabakonandrianina 1988). However, A. manicatum is characterized as a polylectic (Müller 1996) or restricted polylectic (Westrich 2018) species with a wider spectrum of pollen sources. Males of A. manicatum patrolled in the Botanical Garden Halle far more food plant species visited by females (Online Resource 3, Table S2) than the small number of species described as resources used to establish territories so far (Kreisch and Schick 1989; Schick and Sukopp 1998; Westrich 2018; Wirtz et al. 1988). The host plants formed a great diversity of patches differing in size, profitability, and feasibility to become economically monopolized. In large patches, more females aggregated and the number of males interested in mating increased as well. For a territorial male, it becomes impossible to fend off competitors both due to their pure number and the complexity of the large patches. Males abandoned their despotic behavior and switched to a scramble-like search for females foraging in the patch. Hence, large and competitive males were not able to drive smaller competitors out of patches into the extraterritorial matrix and to exclude them from any access to mating. The third prediction was not met. Males were found to form territorial structures only in small patches formed by a few individuals of preferably Stachys (alternatively Ballota, Teucrium), typical for territories of A. manicatum (Kreisch and Schick 1989; Westrich 2018; Wirtz et al. 1988). Nonetheless, male residents in small patches did not always meet the prediction of being consistently either particularly large or small (classic territory holder and sneaker) but covered the whole size range of males. Abandoned territories at "typical" patches were taken over by males of a broad size spectrum. The succeeding male was, though, on average slightly lighter than the previous one. Many of the former territory owners were found later in other patches and it can be assumed that they were not violently dislodged or killed by smaller rivals. Although the fourth prediction on the line of succession was barely fulfilled, there remain reasonable doubts on the underlying mechanism.

In contrast to the expected strict monopolization of resources by the largest males (third prediction), A. manicatum males of all body sizes were found searching for females in food plant patches. Nevertheless, patch occupation should be affected by the competitive abilities of males that depend on patch structure. Large body size is of higher competitive weight in small open patches composed of a few erected stalks of high-quality food plants as Stachys that can be easily overviewed and controlled by a single male. In large patches of dense vegetation, however, males have no chance to economically defend the patch and large body mass is of low competitive value. This effect should lead to a truncated phenotype distribution (Milinski 1988; Parker and Sutherland 1986) with large males controlling the smaller patches by despotic behavior and smaller males scrambling in large patches to obtain some mating. Also, this truncated phenotype distribution was not observed as documented by the composition of male groups (Fig. 5). In A. manicatum, the size-related competitive weight correlation to patch size seems to be balanced by an opposing relation of patch profitability (visiting females in relation to rival number; please note that females might copulate with several males during a visit of a patch). The smaller patches are apparently not that attractive to females either because large patches contain more flowers or females have better possibilities to hide 
while provisioning in dense vegetation. Consequently, small patches that can be controlled by despotic behavior may provide a lower profitability than larger ones. Also, big males can achieve more mating by abandoning despotic behavior and searching dense plant stands visited by many females. On the other hand, defendable small patches of lower quality were occupied by medium-sized to small males. The truncated distribution mimics an ideal free distribution (Fretwell 1972). Each size fraction of males achieved an ideal free distribution of its own (Milinski 1988) as was discernible in the composition of male groups. Thereby males followed the "input matching rule" (Milinski 1988) and distributed in the ratio of patch profitability. Large patches were searched by several males while small patches were occupied by a single male. Two or several small, closely located patches of low quality were combined by repeated flights to and fro. Cases where males shuttled between several patches patrolled by resident rivals can be rated as a floater tactic to look for mating opportunities at several places (Schick and Sukopp 1998; Starks and Reeve 1999). Remarkably, males employed the behavioral tactic matching to their actual situation in the occupied patch (area and structure of patch, present competitors, own body size relative to rivals; see below).

The once achieved distribution of A. manicatum males was not stable over a long time of nesting ( $>80$ days) but changed perpetually. Competing males could not rely on their former assessments because patch profitability changed steadily. Food plants flourished and blossomed out causing an ongoing change in open flowers within a patch. $A$. manicatum males responded to changes in patch quality by occasional excursions to inspect and sample other patches. Also, some few of the ascertained onetime floats were probably such excursions. Males also moved "permanently" to other patches so that patches were obviously exploited according to their changing profitability. The low site fidelity and large non-territoriality parameter measured in this study, the observed shifts (relocations) between patches, the excursions/on-time-floats, the appearance in and disappearance from the study area, and the temporary vanishment of individuals support the high-mobility hypothesis of males rambling the habitat in search for profitable patches.

The territorial manifestation of the RDP in A. manicatum is restricted to distinctive environmental conditions of smallscaled high-quality patches. Another extrinsic prerequisite for territoriality is population density (Alcock et al. 1978; Barrows 1975; Herberstein et al. 2017). Although there is great potential for population density to vary in species that use aggregated resources (Herberstein et al. 2017), food resource availability and population density are to some extent interconnected in A. manicatum. The pollen needed to provision one single average brood cell was calculated to 1005.2 flowers, equivalent to 5.3 plants, of the preferred host Stachys recta (Müller et al. 2006). These flower requirements should balance the number of competitors with exploited host plants as a basic food resource for the whole population including females. Essentially, not the population density as such interferes with territoriality, but patch structure. The composition of the local food plant spectrum and their typical growth habits creates very different selective environments for males that at one time or place may have the potential to monopolize resources when competitor density per patch is low (many small patches), but diminishingly so when patch size and rival density increases. The abandonment of an aggressive resource defense in favor of a scramble competition polygyny at high competitor densities has also been observed in the bee Anthophora plumipes (Stone et al. 1995) and seed bug Neacoryphus bicrucis (McLain 1992). In any case, the resource requirements of females to provision brood cells should provide opportunities for males of all sizes to search for mates.

The male-biased SSD in A. manicatum causes a femalebiased sex ratio (Lampert et al. 2014; Wirtz et al. 1992) according to the equal investment tenet (Fisher 1930). In conjunction with a permanent receptivity of females, the operational sex ratio becomes female biased: quite unusual for insects (Emlen and Oring 1977; Kemp 2018). This could reverse sex roles and induce sexual competition between females. However, females are engaged in lifelong expensive maternal brood care, tying up all their reproduction efforts and relinquishing mating activities to males. Due to the dispersed nesting (Westrich 2018) and collection of brood provisions and nesting materials at scattered resources, $A$. manicatum males have no chance to monopolize individual females. Instead, they are forced into a keen sperm competition of a promiscuous mating system with late male sperm precedence (Alcock 2013b; Alcock et al. 1978; Lampert et al. 2014). Females, at the same time, can circumvent male dominance structures and choose among males by visiting particular patches for the last provision trip(s) before egg laying. Males try to increase their chances to fertilize eggs by monopolizing high-quality patches. Moreover, they raise the nectar reward of the patrolled host plants by interspecific territoriality even toward bumblebees (Graham et al. 2019; Wirtz et al. 1988) to boost the attractiveness of the patch. This interspecific aggression is clearly one driving force of SSD that should not be neglected. However, the flowers of a "typical" territory are not sufficient for individual females to provision their brood cells. Thus, females have to visit all suitable host plants in all sorts of patches according to their yield, thereby connecting patch quality with mating chances of the resident male(s). Although the mating system remains a RDP, the female-biased sex ratio, the diversity of patches, and the late (not last!) male sperm precedence (Lampert et al. 2014) lead to a more balanced siring of offspring and prevent the evolution of dimorphic males. The various mating tactics males can employ, be it territory holder, sneaker, 
floater, or scrambler, are different behavioral phenotypes within one environmentally sensitive conditional strategy (Buzatto et al. 2014) with patch structure and local competitive pressure as key factors. The observed different mate acquisition behaviors are inherently "best of a bad (or good) job" tactics, conferring partial fitness compensation either to individuals with inferior resource holding potential, to different population densities and/or various habitat conditions. Highly plastic mating behaviors are to be expected whenever dynamic extrinsic factors play an important role in the relative fitness of the different alternatives (Buzatto et al. 2014).

Supplementary Information The online version contains supplementary material available at https://doi.org/10.1007/s00265-021-03073-6.

Acknowledgements I am grateful for the possibility to work in the Botanical Garden Halle and the kind forbearance of all horticulturists. Dr. G. Machado and three anonymous reviewers provided helpful comments and suggestions on an earlier draft of the manuscript.

Funding Open Access funding enabled and organized by Projekt DEAL. This study was financially supported by the University of Halle, Institute of Biology/Zoology.

Data availability The dataset generated and analyzed during the current study is available from Share_it_-Open Access und ForschungsdatenRepositorium der Hochschulbibliotheken in Sachsen-Anhalt at http:// dx.doi.org/10.25673/37254.

Open Access This article is licensed under a Creative Commons Attribution 4.0 International License, which permits use, sharing, adaptation, distribution and reproduction in any medium or format, as long as you give appropriate credit to the original author(s) and the source, provide a link to the Creative Commons licence, and indicate if changes were made. The images or other third party material in this article are included in the article's Creative Commons licence, unless indicated otherwise in a credit line to the material. If material is not included in the article's Creative Commons licence and your intended use is not permitted by statutory regulation or exceeds the permitted use, you will need to obtain permission directly from the copyright holder. To view a copy of this licence, visit http://creativecommons.org/licenses/by/4.0/.

\section{References}

Alcock J (1980) Natural selection and the mating systems of solitary bees. Am Sci 68:146-153

Alcock J (1996) The relation between male body size, fighting, and mating success in Dawson's burrowing bee, Amegilla dawsoni (Apidae, Apinae, Anthophorini). J Zool 239:663-674

Alcock J (1997) Competition from large males and the alternative mating tactics of small males of Dawson's burrowing bee (Amegilla dawsoni) (Apidae, Apinae, Anthrophorini). J Ins Behav 10:99-113

Alcock J (2013a) Role of body size in the competition for mates by males of Centris pallida (Anthophorinae: Hymenoptera). Southwest Nat 58:427-430

Alcock J (2013b) Sexual selection and the mating behavior of solitary bees. In: Brockmann HJ, Roper TJ, Naguib M, Mitani JC, Simmons LW, Barrett L (eds) Advances in the study of behavior, vol 45. Elsevier Academic Press Inc, San Diego, pp 1-48
Alcock J, Eickwort GC, Eickwort KR (1977a) The reproductive behavior of Anthidium maculosum (Hymenoptera: Megachilidae) and the evolutionary significance of multiple copulations by females. Behav Ecol Sociobiol 2:385-396

Alcock J, Gordh G, Hubbard J, Pyle RW, Kirkendall L, Ponder TL, Zalom FG (1978) The ecology and evolution of male reproductive behavior in the bees and wasps. Zool J Linn Soc 64:293-326

Alcock J, Jones CE, Buchmann SL (1977b) Male mating strategies in the bee Centris pallida Fox (Anthophoridae: Hymenoptera). Am Nat 111:145-155

Barrows EM (1975) Territoriality in male bees (Hymenoptera, Apoidea). J NY Entomol Soc 83:280-281

Blanckenhorn WU (2005) Behavioral causes and consequences of sexual size dimorphism. Ethol 111:977-1016

Bosch J, Vicens N (2005) Sex allocation in the solitary bee Osmia cornuta: do females behave in agreement with Fisher's theory? Behav Ecol Sociobiol 59:124-132

Brown JL (1964) The evolution of diversity in avian territorial systems. Wilson Bull 76:160-169

Buzatto BA, Tomkins JL, Simmons LW (2014) Alternative phenotypes within mating systems. In: Shuker DM, Simmons LW (eds) The evolution of insect mating systems. Oxford University Press, Oxford, pp 106-128

Cane JH (1987) Estimation of bee size using intertegular span (Apoidea). J Kans Entomol Soc 60:145-147

Eickwort GC (1977) Male territorial behavior in the mason bee Hoplitis anthocopoides (Hymenoptera: Megachilidae). Anim Behav 25:542-554

Emlen ST, Oring LW (1977) Ecology, sexual selection and the evolution of mating systems. Science 197:215-223

Fisher RA (1930) The genetical theory of natural selection. Clarendon Press, Oxford

Fisher RA, Corbet AS, Williams CB (1943) The relation between the number of species and the number of individuals in a random sample of an animal population. J Anim Ecol 12:42-58

Fretwell SD (1972) Populations in a seasonal environment. Princeton University Press, Princeton

Garcia GF, Ornosa C (1999) Territorial behavior associate with the resource defense polygyny of Anthidium florentinum (Fabricius, 1775) (Hymenoptera, Megachilidae). Bol Asoc Espan Entomol 23:41-51

Gibbs J, Sheffield CS (2009) rapid range expansion of the wool-carder bee, Anthidium manicatum (Linnaeus) (Hymenoptera: Megachilidae), in North America. J Kans Entomol Soc 82:21-29

Graham KK, MacLean MG (2018) Presence-only modeling is ill-suited for a recent generalist invader, Anthidium manicatum. Ecol Indic 89:56-62

Graham KK, Eaton K, Obrien I, Starks PT (2019) Anthidium manicatum, an invasive bee, excludes a native bumble bee, Bombus impatiens, from floral resources. Biol Invasions 21:1089-1099

Herberstein ME, Painting CJ, Holwell GI (2017) Scramble competition polygyny in terrestrial arthropods. In: Naguib M, Podos J, Simmons LW, Barrett L, Healy SD, Zuk M (eds) Advances in the study of behavior, vol 49. Elsevier Academic Press Inc, San Diego, pp 237-295

Hughes WOH, Oldroyd BP, Beekman M, Ratnieks FLW (2008) Ancestral monogamy shows kin selection is key to the evolution of eusociality. Science 320:1213-1216

Jaycox ER (1967) Territorial behavior among males of Anthidium banningense (Hymenoptera: Megachilidae). J Kans Entomol Soc 40:565

Kemp DJ (2018) Habitat selection and territoriality. Insect behavior: from mechanisms to ecological and evolutionary consequences. Oxford Univ Press, New York. 
Kim JY, Thorp RW (2001) Maternal investment and size-number tradeoff in a bee, Megachile apicalis, in seasonal environments. Oecologia (berlin) 126:451-456

Kokko H, Klug H, Jennions MD (2014) Mating systems. In: Shuker DM, Simmons LW (eds) The evolution of insect mating systems. Oxford University Press, Oxford, pp 42-58

Kreisch B, Schick B (1989) Bevorzugt die Wollbiene Anthidium manicatum einige wenige Futterpflanzen? Mitt Pollichia (bad Dürkheim) 76:171-183

Lampert KP, Pasternak V, Brand P, Tollrian R, Leese F, Eltz T (2014) 'Late' male sperm precedence in polyandrous wool-carder bees and the evolution of male resource defense in Hymenoptera. Anim Behav 90:211-217

McLain DK (1992) Population-density and the intensity of sexual selection on body length in spatially or temporally restricted natural-populations of a seed bug. Behav Ecol Sociobiol 30:347-356

Milinski M (1988) Games fish play - making decisions as a social forager. Trends Ecol Evol 3:325-330

Müller A (1996) Host-plant specialization in western palearctic Anthidiine bees (Hymenoptera: Apoidea: Megachilidae). Ecol Monogr 66:235-257

Müller A, Diener S, Schnyder S, Stutz K, Sedivy C, Dorn S (2006) Quantitative pollen requirements of solitary bees: implications for bee conservation and the evolution of bee-flower relationships. Biol Conserv 130:604-615

Müller UG (1987) Dimorphic males in the European wool-carder bee Anthidium manicatum (Megachilidae: Hymenoptera). MsA Thesis, Cornell University

Nilsson LA, Rabakonandrianina E (1988) Chemical signalling and monopolization of nectar resources by territorial Pachymelus limbatus (Hymenoptera, Anthophoridae) male bees in Madagascar. J Zool 215:475

O’Neill KM, Pearce AM, O'Neill RP, Miller RS (2010) Offspring size and sex ratio variation in a feral population of alfalfa leafcutting bees (Hymenoptera: Megachilidae) Ann Entomol Soc Am 103:775-784

Parker GA, Sutherland WJ (1986) Ideal free distributions when individuals differ in competitive ability - phenotype-limited ideal free models. Anim Behav 34:1222-1242

Paxton R-J (2005) Male mating behavior and mating systems of bees: an overview. Apidol 36:145-156

Pechuman LL (1967) Observations on the behavior of the bee Anthidium manicatum (L.). J NY Entomol Soc 75:68

Schick B, Sukopp H (1998) Plant-pollination systems in urban parks and gardens: flower preferences of the solitary wild bee (Anthidium manicatum L.) in the botanical gardens of Berlin-Dahlem. Z Oekol Natursch 7:73-83

Seidelmann K (2014) Optimal progeny body size in a solitary bee, Osmia bicornis (Apoidea: Megachilidae). Ecol Entomol 39:656-663

Seidelmann K, Ulbrich K, Mielenz N (2010) Conditional sex allocation in the Red Mason bee, Osmia rufa. Behav Ecol Sociobiol 64:337-347
Severinghaus LL, Kurtak BH, Eickwort GC (1981) The reproductive behavior of Anthidium manicatum (Hymenoptera: Megachilidae) and the significance of size for territorial males. Behav Ecol Sociobiol 9:51-58

Simmons LW, Tomkins JL, Alcock J (2000) Can minor males of Dawson's burrowing bee, Amegilla dawsoni (Hymenoptera: Anthophorini) compensate for reduced access to virgin females through sperm competition? Behav Ecol 11:319-325

Soper J, Beggs JR (2013) Assessing the impact of an introduced bee, Anthidium manicatum, on pollinator communities in New Zealand. N Z J Bot 51:213-228

Starks PT, Reeve HK (1999) Condition-based alternative reproductive tactics in the wool-carder bee, Anthidium manicatum. Ethol Ecol Evol 11:71-75

Stone GN, Loder PMJ, Blackburn TM (1995) Foraging and courtship behavior in males of the solitary bee Anthophora plumipes (Hymenoptera: Anthophoridae): thermal physiology and the roles of body size. Ecol Entomol 20:169-183

Strange JP, Koch JB, Gonzalez VH, Nemelka L, Griswold T (2011) Global invasion by Anthidium manicatum (Linnaeus) (Hymenoptera: Megachilidae): assessing potential distribution in North America and beyond. Biol Invas 13:2115-2133

Stubblefield JW, Seger J (1994) Sexual dimorphism in the Hymenoptera. In: Short RV, Balaban EE (eds) The differences between the sexes. Cambridge University Press, Cambridge (MA), pp 71-103

Sugiura N (1991) Male territoriality and mating tactics in the woolcarder bee, Anthidium septempinosum Lepeletier (Hymenoptera: Megachilidae). J Ethol 9:95-103

Thornhill R, Alcock J (1983) The evolution of insect mating systems. Harvard University Press, Cambridge

Tomkins JL, Simmons LW, Alcock J (2001) Brood-provisioning strategies in Dawson's burrowing bee, Amegilla dawsoni (Hymenoptera: Anthophorini). Behav Ecol Sociobiol 50:81-89

Villalobos EM, Shelly TE (1991) Correlates of male mating success in two species of Anthidium bees (Hymenoptera: Megachilidae). Behav Ecol Sociobiol 29:47-54

Westrich P (2018) Die Wildbienen Deutschlands, 1st edn. Verlag Eugen Ulmer, Stuttgart

Wirtz P, Kopka S, Schmoll G (1992) Phenology of two solitary bees, Anthidium manicatum and A. florentinum (Hymenoptera: Megachilidae). J Zool 228:641-651

Wirtz P, Scabados M, Pethig H, Plant J (1988) An extreme case of interspecific territoriality: male Anthidium manicatum (Hymenoptera, Megachilidae) wound and kill intruders. Ethol 78:159-167

Publisher's Note Springer Nature remains neutral with regard to jurisdictional claims in published maps and institutional affiliations. 